\title{
Correction to: Synovial Chondromatosis
}

\author{
Eric L. Staals
}

\section{Correction to: Chapter 28 in: P. Picci et al. (eds.), Diagnosis of Musculoskeletal Tumors and Tumor-like Conditions, https://doi.org/10.1007/978-3-030-29676-6_28}

Chapter 28 was inadvertently published with the following error:

The figure on page 131 was misplaced. The correct figure has been included in this erratum. The chapter has now been updated.

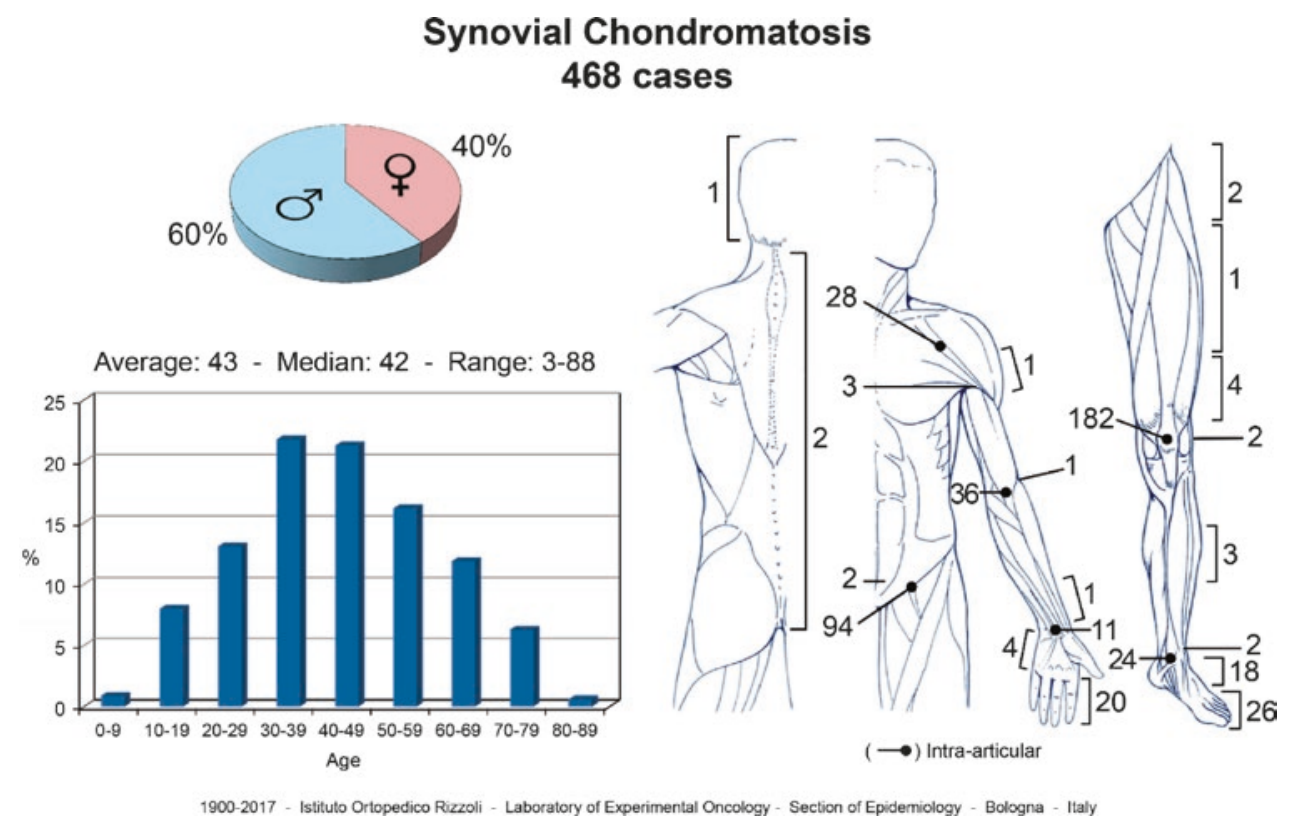

The updated online version of this chapter can be found at https://doi.org/10.1007/978-3-030-29676-6_28 